\title{
Preliminary attempt at biological control of coconut leaf eating caterpillar, Opisina arenosella Walker using two Trichogramma species
}

\author{
S.K. Jalali ${ }^{* 1}$, T. Venkatesan ${ }^{1}$, K.S. Murthy ${ }^{1}$, T.V. Bhaskaran ${ }^{1}$ and Y. Lalitha ${ }^{1}$
}

\begin{abstract}
A preliminary attempt was made for biological control of coconut leaf eating caterpillar, Opisina arenosella Walker, by releasing two Trichogramma species viz. T. chilonis Ishii and T. embryophagum Hartig @ 1,000 to 4,000 parasitised eggs per palm in Bangalore, India. The mean percent reduction in larval population by $75.6,60.0,33.3$ and $50.0 \%$ in T. chilonis and $88.8 \%, 175.0,66.7$ and $75.0 \%$ in T. embryophagum was recorded in treated palms during $1^{\text {st }}, 2^{\text {nd }}, 3^{\text {rd }}$ and $4^{\text {th }}$ generation of the pest compared to untreated control. There was nonsignificant difference between various release rates irrespective of the species, indicating that lower release rate of 1,000 parasitised eggs $/ \mathrm{palm}$ as adequate. On sentinel egg cards, parasitism was low $2.0-5.0 \%, 0.0-2.0 \%$ and $0.0 \%$ in T. chilonis, and T. embryophagum released palms and untreated control palms, respectively. The field trial gave an indication that Trichogramma could be a potential parasitoid against $O$. arenosella and it is suggested that the parasitoids could be released and tested on a large scale in endemic areas to authenticate efficacy.
\end{abstract}

Key words: Biological control, coconut, Opisina arenosella, Trichogramma embryophagum, T. chilonis.

${ }^{1}$ Project Directorate of Biological Control, Post bag No. 2491, H. A. Farm Post, Bellary Road, Bangalore 560024, India; 'Corresponding author; E-mail: jalalisk@ yahoo.com 


\section{Introduction}

Oecophorid caterpillar Opisina arenosella Walker is a serious pest of coconut in many south Asian countries. Severe infestation results in leaves appearing scorched with drastic reduction in the yield (Ramachandran et al., 1979). In severe outbreaks thousands of palms are affected and all fronds except 3 or 4 youngest ones, are killed, followed by drastic reduction in production (Lever, 1969). Many other plants of palm family have been recorded as alternate or minor hosts of $O$. arenosella (Cock and Perera, 1987). The pest infests the coconut palm throughout the year from mild to medium densities, but under favourable conditions it becomes an outbreak pest and affects thousands of palms severely. The pest has 4-5 generations in a year and population increase has been attributed to high humidity and decrease to high temperature, much sunshine and heavy rain (Sathiamma et al., 1974). High temperature evidently affected natural enemies adversely, leading to pest population increase in summer season (Nadarajan and ChannaBsavanna, 1980).

Many attempts have been made to control this pest, mainly with cultural or biological methods. One early method advocated was to remove infested leaves to reduce the larval population and use of light traps (Cock and Perera, 1987). Augmentative releases of larval and pupal parasitoids both in Sri Lanka and India has played major role in suppressing the population of $O$. arenosella. Successful biological control is possible if large area is treated particularly for the pest like $O$. arenosella so that its spread is checked. One such possibility of using parasitoids on very large scale is utilising egg parasitoid Trichogramma. Jalali et al. (2002) selected T. embryophagum Hartig as most promising species out of eleven species screened for field-testing against $O$. arenosella based on the laboratory study. Trichogramma species have been used to control lepidopteran pests in many countries (Hassan, 1989). Earlier field record in India suggested presence of $T$. chilonis Ishii parasitising eggs of $O$. arenosella (Dharmaraju, 1952; Nirula, 1956).
In order to test the efficacy of two Trichogramma spp. viz., $T$. chilonis and $T$. embryophagum for the control of $O$. arenosella, a field trial was conducted at Allalasandra village in Bangalore rural district (Karnataka) and results of the trial are presented in this paper.

\section{Materials and methods}

Trichogramma chilonis and $T$. embryophagum used in the present study were maintained on the eggs of Corcyra cephalonica (Stainton) in the laboratory. Before initiation of the field trial, nucleus culture of both the species was exposed to $O$. arenosella eggs for 3 generations for their adaptation to the new host.

The field trial was laid out at Allalasandra village having coconut palms of about ten feet tall. Prior to releases of Trichogramma species, pest population was monitored. The releases in each generation were carried out based on the pupae and empty pupal cases in the sampling, which gave indication of egg laying in the field. The releases were made at weekly interval and during each generation 3 releases were made. The releases were discontinued when majority of the sampling units had larvae in the $2^{\text {nd }}$ or $3^{\text {rd }}$ instars. The releases were made for 4 generations during the year. The study was conducted from February to December 2004.

The treatments imposed were $\mathrm{T}_{1}=$ release of T. chilonis @ 1,000,2,000,3,000 and 4,000 parasitised eggs/palm, $\mathrm{T}_{2}=$ release of $T$. embryophagum @1,000,2,000,3,000 and 4,000 parasitised eggs/palm and $\mathrm{T}_{3}=$ untreated control. Each treatment (release rate wise) was replicated 5 times, thus 20 palms were treated with $T$. chilonis and another 20 with T. embryophagum. For each release rate one row of untreated control was kept and the species was separated by a row of palms.

The release of both Trichogramma species was carried out prior to its emergence from the host eggs, i.e. $8^{\text {th }}$ day after parasitisation. Tricho card bit containing 1,000, 2,000, 3,000 and 4,000 
parasitised eggs by Trichogramma were stapled near the crown of the palm.

The egg parasitism was recorded based on sentinel cards. The laboratory reared $O$. arenosella eggs @ 20 nos./card/palm kept in nylon pouch was hanged on palms one day after $3^{\text {rd }}$ release. Thus 5 cards were hang near the crown under each release rate and a total of 20 sentinel cards per species and untreated control were hang. The egg cards were collected $24 \mathrm{~h}$ after placement and were observed for parasitism in each generation.

The observation of the larval population was taken one week after $3^{\text {rd }}$ release in each generation, twice under each release rate. In each release rate, 15 leaflets/palm were cut and brought to the laboratory to record larval population. The data recorded on the larval population was analysed using 2-way ANOVA to observe differences with untreated control. As differences were observed between treatment and untreated control, data was analysed again between the two species of the parasitoid to observe the differences between them. Per cent reduction in larval population in the treated palms with $T$. chilonis and $T$. embryophagum over untreated control palms was calculated by the formula $\mathrm{C}-\mathrm{T} / \mathrm{C} \times 100$, where $\mathrm{C}=$ control, $\mathrm{T}=$ treatments as suggested by Pradhan (1983).

\section{Results and discussions}

The results of the field trial to compare the efficacy of releases of $T$. chilonis and $T$. embryophagum in comparison with untreated control palms are presented in Table 1. During the $1^{\text {st }}$ generation of $O$. arenosella, lower larval population was recorded in $T$. embryophagum (0.1 larva/leaflet) compared to $T$. chilonis $(0.22$ larva/leaflet) released palms, however, larval population was at par between these two treatments but significantly lower compared to untreated control $(\mathrm{SEM}=0.06 ;$ d. f. $=2 ; \mathrm{LSD}=$ $0.16 ; \mathrm{P}=0.05 \%)$. However, there was nonsignificant difference between release rates. The results signify that even at lower release rate of 1000 parasitised eggs/palm, both species could reduce the pest population significantly. During the $2^{\text {nd }}$ generation also, larval population was significantly less in treated palms $(\mathrm{SEM}=0.03$; d. f. $=2 ; \mathrm{LSD}=0.08 ; \mathrm{P}=0.05 \%)$. Similar trend was observed in $3^{\text {rd }}$ and $4^{\text {th }}$ generations also compared to untreated control. The mean percent reduction in larval population by $75.6,60.0,33.3$ and $50.0 \%$ in $T$. chilonis and $88.8 \%, 175.0,66.7$ and $75.0 \%$ in $T$. embryophagum was recorded in treated palms during $1^{\text {st }}, 2^{\text {nd }}, 3^{\text {rd }}$ and $4^{\text {th }}$ generation of the pest compared to untreated control.

The data analysed to test differences between two species viz. T. chilonis and $T$. embryophagum are presented in Table 2. The analysis revealed that release of $T$. embryophagum was significantly superior to $T$. chilonis during the $1^{\text {st }}$ generation of the pest $(\mathrm{SEM}=0.04 ; \mathrm{D} . \mathrm{f} .=1 ; \mathrm{LSD}=0.11 ; \mathrm{P}=0.05 \%)$. However, there was non-significant difference in larval population during $2^{\text {nd }}, 3^{\text {rd }}$ and $4^{\text {th }}$ generations. Since there was non-significant difference between various release rates, lower release rate of 1,000 parasitised eggs/palm can be taken up for the large-scale trial. The release rate of 1,000 parasitised eggs/palm converts to 180,000 parasitised eggs/ha.

The egg parasitism recorded on the sentinel cards indicated that $T$. chilonis parasitised 2.0, 1.0, 3.0 and 5.0\% eggs compared to $0.0,1.0,2.0$ and $2.0 \%$ eggs by $T$. embryophagum and nil in untreated control. Though percent egg parasitism on sentinel cards was very low, the indication on ability of released Trichogrammatids to search host in coconut ecosystem was established. The observation of recovery of both species in the field is in accordance with Kanagaratnam (1975) in Sri Lanka, who reported initial recovery of $T$. brasiliense Ashmead but not establishment. Nagarkatti (1973) reported the release of $T$. chilonis@730,000 at each of four sites in Andhra Pradesh, but it failed to establish. It was advocated that use of arboreal species for coconut habitat would provide better results. In the present study, T. embryophagum used is arboreal species and it proved better than $T$. chilonis particularly during the $1^{\text {st }}$ generation of the pest. 
Table 1. Opisina arenosella larval population per leaflet in Trichogramma spp. treated and untreated palms in Bangalore

\begin{tabular}{|c|c|c|c|c|c|c|c|c|c|c|}
\hline \multirow{3}{*}{ Treatments } & \multicolumn{4}{|c|}{$1^{\text {st }}$ generation } & \multirow{3}{*}{$\begin{array}{l}\text { Mean } \\
(\mathrm{T})^{*}\end{array}$} & \multicolumn{4}{|c|}{$2^{\text {nd }}$ generation } & \multirow{3}{*}{$\begin{array}{c}\text { Mean } \\
(\mathrm{T})^{*}\end{array}$} \\
\hline & \multicolumn{4}{|c|}{ Release rate @ parasitised eggs/palm } & & \multicolumn{4}{|c|}{ Release rate @ parasitised eggs/palm } & \\
\hline & 1,000 & 2,000 & 3,000 & 4,000 & & 1,000 & 2,000 & 3,000 & 4,000 & \\
\hline T. chilonis & 0.30 & 0.10 & 0.30 & 0.20 & $0.22^{\mathrm{b}}$ & 0.10 & 0.10 & 0.10 & 0.00 & $0.08^{\mathrm{b}}$ \\
\hline T. embryophagum & 0.10 & 0.10 & 0.10 & 0.10 & $0.10^{\mathrm{b}}$ & 0.10 & 0.10 & 0.00 & 0.00 & $0.05^{\mathrm{b}}$ \\
\hline Untreated control & 0.90 & 0.90 & 0.90 & 0.90 & $0.90^{\mathrm{a}}$ & 0.20 & 0.20 & 0.20 & 0.20 & $0.20^{\mathrm{a}}$ \\
\hline \multirow[t]{2}{*}{ Mean (RR) } & 0.43 & 0.36 & 0.43 & 0.43 & & 0.13 & 0.13 & 0.10 & 0.07 & \\
\hline & $\mathbf{T}$ & $\mathbf{R R}$ & \multicolumn{2}{|c|}{$\mathbf{T} \times \mathbf{R R}$} & & $\mathbf{T}$ & $\mathbf{R R}$ & \multicolumn{2}{|c|}{$\mathbf{T} \times \mathbf{R R}$} & \\
\hline SEM & 0.06 & 0.07 & \multicolumn{2}{|c|}{0.12} & & 0.06 & 0.07 & \multicolumn{2}{|c|}{0.12} & \\
\hline LSD at $5 \%$ & 0.16 & NS & \multicolumn{2}{|c|}{ NS } & & 0.16 & NS & \multicolumn{2}{|c|}{ NS } & \\
\hline
\end{tabular}

* Means followed by the same letter is not different significantly at $\mathrm{P}=0.05 \% ; \mathrm{T}=$ Treatment, $\mathrm{RR}=$ Release rate, $\mathrm{T} x \mathrm{RR}$ is interaction

\begin{tabular}{|c|c|c|c|c|c|c|c|c|c|c|}
\hline \multirow{3}{*}{ Treatments } & \multicolumn{4}{|c|}{$3^{\text {rd }}$ generation } & \multirow{3}{*}{$\begin{array}{l}\text { Mean } \\
(\mathrm{T})^{*}\end{array}$} & \multirow{2}{*}{\multicolumn{4}{|c|}{$\begin{array}{c}4^{\text {th }} \text { generation } \\
\text { Release rate @ parasitised eggs/palm }\end{array}$}} & \multirow{3}{*}{$\begin{array}{l}\text { Mean } \\
(\mathrm{T})^{*}\end{array}$} \\
\hline & \multicolumn{4}{|c|}{ Release rate@ @arasitised eggs/palm } & & & & & & \\
\hline & 1,000 & 2,000 & 3,000 & 4,000 & & 1,000 & 2,000 & 3,000 & 4,000 & \\
\hline T. chilonis & 0.20 & 0.20 & 0.10 & 0.20 & $0.18^{\mathrm{b}}$ & 0.20 & 0.20 & 0.10 & 0.20 & $0.18^{\mathrm{b}}$ \\
\hline T. embryophagum & 0.10 & 0.10 & 0.10 & 0.10 & $0.10^{\mathrm{b}}$ & 0.10 & 0.10 & 0.10 & 0.10 & $0.10^{\mathrm{b}}$ \\
\hline Untreated control & 0.30 & 0.30 & 0.30 & 0.30 & $0.30^{\mathrm{a}}$ & 0.40 & 0.40 & 0.40 & 0.40 & $0.40^{\mathrm{a}}$ \\
\hline \multirow[t]{2}{*}{ Mean (RR) } & 0.20 & 0.20 & 0.17 & 0.20 & & 0.23 & $0 . .23$ & 0.20 & 0.23 & \\
\hline & $\mathbf{T}$ & $\mathbf{R R}$ & \multicolumn{2}{|c|}{ Tx RR } & & $\mathbf{T}$ & $\mathbf{R R}$ & \multicolumn{2}{|c|}{ Tx RR } & \\
\hline SEM & 0.04 & 0.05 & \multicolumn{2}{|c|}{0.08} & & 0.04 & 0.05 & \multicolumn{2}{|c|}{0.09} & \\
\hline LSD at $5 \%$ & 0.12 & NS & \multicolumn{2}{|c|}{ NS } & & 0.12 & NS & \multicolumn{2}{|c|}{ NS } & \\
\hline
\end{tabular}

* Means followed by the same letter is not different significantly at $\mathrm{P}=0.05 \% ; \mathrm{T}=$ Treatment, $\mathrm{RR}=$ Release rate, $\mathrm{T} \times \mathrm{RR}$ is interaction 
Table 2. Opisina arenosella larval population per leaflet between two Trichogramma species treated palms

\begin{tabular}{|c|c|c|c|c|c|c|c|c|c|c|}
\hline \multirow{3}{*}{ Treatments } & \multicolumn{4}{|c|}{$1^{\text {st }}$ generation } & \multirow{3}{*}{$\begin{array}{c}\text { Mean } \\
(\mathrm{T})^{*}\end{array}$} & \multicolumn{4}{|c|}{$2^{\text {nd }}$ generation } & \multirow{3}{*}{ Mean $(\mathrm{T})$} \\
\hline & \multicolumn{4}{|c|}{ Release rate @ parasitised eggs/palm } & & \multicolumn{4}{|c|}{ Release rate @ parasitised eggs/palm } & \\
\hline & 1,000 & 2,000 & 3,000 & 4,000 & & 1,000 & 2,000 & 3,000 & 4,000 & \\
\hline T. chilonis & 0.30 & 0.10 & 0.30 & 0.20 & $0.22^{\mathrm{a}}$ & 0.10 & 0.10 & 0.10 & 0.00 & 0.08 \\
\hline T. embryophagum & 0.10 & 0.10 & 0.10 & 0.10 & $0.1^{\mathrm{b}}$ & 0.10 & 0.10 & 0.00 & 0.00 & 0.05 \\
\hline \multirow[t]{2}{*}{ Mean (RR) } & 0.20 & 0.10 & 0.20 & 0.15 & & 0.10 & 0.10 & 0.05 & 0.00 & \\
\hline & $\mathbf{T}$ & $\mathbf{R R}$ & \multicolumn{2}{|c|}{$\mathbf{T} \times \mathbf{R R}$} & & $\mathbf{T}$ & $\mathbf{R R}$ & \multicolumn{2}{|c|}{$\mathbf{T} \times \mathbf{R R}$} & \\
\hline SEM & 0.06 & 0.07 & \multicolumn{2}{|c|}{0.12} & & 0.06 & 0.07 & \multicolumn{2}{|c|}{0.12} & \\
\hline LSD at $5 \%$ & 0.16 & NS & \multicolumn{2}{|c|}{ NS } & & NS & NS & \multicolumn{2}{|c|}{ NS } & \\
\hline
\end{tabular}

* Means followed by the same letter is not different significantly at $\mathrm{P}=0.05 \%$; $\mathrm{T}=$ Treatment, $\mathrm{RR}=$ Release rate, $\mathrm{T} \mathrm{x} \mathrm{RR}$ is interaction

\begin{tabular}{|c|c|c|c|c|c|c|c|c|c|c|}
\hline \multirow{3}{*}{ Treatments } & \multicolumn{4}{|c|}{$3^{\text {rd }}$ generation } & \multirow{3}{*}{$\begin{array}{c}\text { Mean } \\
(\mathrm{T})\end{array}$} & \multicolumn{4}{|c|}{$4^{\text {th }}$ generation } & \multirow{3}{*}{ Mean $(\mathrm{T})$} \\
\hline & \multicolumn{4}{|c|}{ Release rate @ parasitised eggs/palm } & & \multicolumn{4}{|c|}{ Release rate @ parasitised eggs/palm } & \\
\hline & 1,000 & 2,000 & 3,000 & 4,000 & & 1,000 & 2,000 & 3,000 & 4,000 & \\
\hline T. chilonis & 0.20 & 0.20 & 0.1 & 0.2 & 0.18 & 0.20 & 0.20 & 0.10 & 0.20 & 0.18 \\
\hline T. embryophagum & 0.10 & 0.10 & 0.1 & 0.1 & 0.10 & 0.10 & 0.10 & 0.10 & 0.10 & 0.10 \\
\hline \multirow[t]{2}{*}{ Mean (RR) } & 0.15 & 0.20 & 0.17 & 0.2 & & 0.15 & 0.15 & 0.10 & 0.15 & \\
\hline & $\mathbf{T}$ & RR & \multicolumn{2}{|c|}{$\mathbf{T} \times \mathbf{R R}$} & & $\mathbf{T}$ & $\mathbf{R R}$ & \multicolumn{2}{|c|}{$\mathbf{T} \times \mathbf{R R}$} & \\
\hline SEM & 0.04 & 0.05 & \multicolumn{2}{|c|}{0.08} & & 0.04 & 0.05 & \multicolumn{2}{|c|}{0.09} & \\
\hline LSD at $5 \%$ & NS & NS & \multicolumn{2}{|c|}{ NS } & & NS & NS & \multicolumn{2}{|c|}{ NS } & \\
\hline
\end{tabular}

* Means followed by the same letter is not different significantly at $\mathrm{P}=0.05 \%$; $\mathrm{T}=$ Treatment, $\mathrm{RR}=\mathrm{Release}$ rate, $\mathrm{T} \mathrm{x} \mathrm{RR}$ is interaction 
The preliminary field trail with two species of Trichogramma has given encouraging results though, pest population was low during the study. However, there is need for large-scale trial to possibly demonstrate the efficacy in endemic areas of $O$. arenosella in India.

\section{Acknowledgement}

Authors are thankful to Dr. R.J. Rabindra, Project Director for providing necessary facilities for carrying out the work.

\section{References}

Cock, M.J.W. and Perera, P.A.C.R. 1987. Biological control of Opisina arenosella Walker (Lepidoptera: Oecophoridae). BNI 8: 283-309.

Dharmaraju, E. 1952. The biological control of the black headed caterpillar of coconut (Nephantis serinopa M.) in the East Godavari district of Madras state. Indian Cocon. J. 5: 171-175.

Hassan, S.A. 1989. Selection of suitable Trichogramma species to control the codling moth Cydia pomonella and the summer fruit tortrix moths Adoxophyes orana and Pandermis heparana (Lep.: Tortricidae). Entomophaga 34: 19-27.

Jalali, S.K., Singh, S.P. and Venkatesan, T. 2002. Selection of promising species of trichogrammatid egg parasitoid for field evaluation against coconut leaf eating caterpillar, Opisina arenosella Walker. J. Plant. Crops 30: 30-32.

Kanagaratnam, P. 1975. Report of the Crops Protection Division. Ceylon Cocon. Quart. 26: 51-56.
Lever, R.J.A.W. 1969. Notes on outbreaks, the parasites and habits of the coconut moth Artona catoxantha Hamps. Malayan Agric. J. 36: 20-27.

Nadarajan, L. and ChannaBsavanna, G.P. 1980. Population dynamics of coconut black headed caterpillar, Nephantis serinopa Meyrick (Lepidoptera: Cryptophasidae) and its parasites. Mysore J. Agric. Sci. 14: 533-541.

Nagarkatti, S. 1973. Biological control campaign against Nephantis serinopa Meyr. in India in the light of modern concepts. J. Plant. Crops 1: 28-31.

Nirula, K.K. 1956. Investigations on the pests of coconut palm. Part III. Nephantis serinopa Meyrick. Indian Cocon. J. 9: 101-131.

Pradhan, S. 1983. Agricultural Entomology and Pest Control. Indian Council of Agricultural Research, New Delhi, 83 pp.

Ramachandran, C.P., Ponnamma, K.N., Abdulla Koya, K.M. and Kurian, C. 1979. The coconut leaf-eating caterpillar, Nephantis serinopa Meyrick, a review. Philippines J. Cocon. Stud. 4: 9-17.

Sathiamma, B., George, M.V. and Kurian, C. 1974. Seasonal variations in the larval population of Nephantis serinopa Meyrick in the field as correlated with meteorological factors. In: Proc. First Natl. Symp. Plantn. Crops, K.M. Nayar (Ed.). December 8 - 9, 1972, Trivandrum, India. J. Plant. Crops 1 (Suppl.): 161-163. 